\title{
Changeability of Production Management Systems
}

\author{
M.S. Hoogenraad and J.C. Wortmann \\ Faculty of Management and Organization, University of Groningen \\ Landleven 5, P.O. Box 800, 9700 AV Groningen, the Netherlands \\ Tel. +31 50-363 3864 \\ j.c.wortmann@rug.nl \\ Marco.Hoogenraad@infor.com
}

\begin{abstract}
.
Modern production management systems consist of transaction processing systems and decision enhancement systems. A clear example of two such components are an ERP systems and APS systems. These systems are often standard software systems, and therefore suitable for many different situations. This paper analyses the combination of ERP and APS from the perspective of change. The paper builds on a classification of ERP-APS integrations and an analysis of changeability of ERP systems. The paper elaborates on issues encountered when changing ERP-APS integrations. The main conclusion is that such changes are technically complex because of different technologies and different data models used. Therefore, end user education and training is emphasized Moreover, they are organizationally complex because many stakeholders are involved.
\end{abstract}

\section{Introduction}

Production management systems (PMS) have been around for several decades now. In the last 20 years, most implemented information systems for production management were ERP systems (Klaus et al. 2000). These systems are standard software packages aiming at integrated transaction processing across a company (Wortmann, 1998). Because of their focus on transaction processing, ERP systems can be called data-oriented. Because of their standard software nature, ERP systems are highly parameterised.

Despite their focus on transaction processing, many ERP systems have their roots in production planning and control (PPC). The abbreviation Enterprise Resource Planning is derived from Manufacturing Resource Planning (MRPII), which in turn is derived from MRP I - Material Requirements Planning. These planning systems and frameworks were well established before ERP became mature. Production 
planning and control applications are delivered together with transaction processing as integral part of an ERP package suitable for the market of manufacturing industries.

However, these PPC applications as parts of an ERP suite of software are not always satisfying the needs of production management. ERP planning software is essentially not interactive software but requires batch runs, which has to occur over night or in the weekend. In addition, ERP planning software does not use advanced user interface (UI) capabilities. Moreover, ERP planning software cannot deploy advanced iterative algorithms. Finally, it is restricted to the transaction processing as modelled in the ERP package, and, it is therefore limited to the application areas chosen in a particular ERP-package. Consequently, it is not easy to use ERP planning functionality in areas such supply chain management e.g. for what-if analysis or real-time control of large data volumes.

Because of the drawbacks of ERP software planning functionality, other PPC software has come to the PMS market. Under the name of Advanced Planning Systems (APS), standard software has been offered which is interactive (Stadtler and Kilger., 2002). APS offers the user a high-resolution UI, fast iterative algorithmic calculations, and provides options to go beyond the domain covered by ERP transactions. APS software modules operate on a fast (InRam) database, often called an object store, which is extracted from the transaction database.

Consequently, many production management systems have now advanced planning software modules integrated with ERP planning and transaction processing (Tarn et al., 2002). This paper analyses such production management systems consisting of ERP and APS from the perspective of change. The relatively vast amount of literature on ERP implementations has shown that enterprise information systems are never "ready": systems continue to be changed (Botta-Genoulaza et al, 2005).

For production management systems, there are several reasons for change. First of all, the fact that systems are being used, leads to requirements for more advanced or sophisticated functionality. Secondly, the nature of planning problems changes when companies invest in (or withdraw from) their product portfolio, market approach, governance and collaboration structure or manufacturing resources. Thirdly, change may induced by developments in ICT, such as upgrades in one of the employed standard software packages. These reasons constitute a background for the change perspective taken in this paper.

\section{Problem statement and approach}

This paper will investigate the changeability of production management systems consisting of a transaction processing backbone and one or more planning modules. The transaction processing backbone is implemented by an ERP package. The planning functionality is partly implemented by APS software. However, as will be discussed later, there is usually a mixture of ERP planning software, APS planning software and other means of planning (Liu et al., 2002; Wiers, 2002). Against this background, the problem statement can be phrased as follows. Given an implemented 
production management system consisting of ERP and APS, which issues have to be addressed when there is a need for change?

The above problem statement can be decomposed into several smaller questions:

- What types of interfaces exist between ERP transaction processing and APS?

- What are the changeability issues of implemented ERP packages for transaction processing?

- What are the changeability issues of implemented planning modules? Is there a difference between APS and ERP planning modules?

The first question, on ERP-APS integration, was investigated by the authors, and the results have been laid down in an earlier paper. This paper is summarized below, in Section 3. The second question, on changeability of ERP for transaction processing, was also researched by the authors (and others). The result is presented in Section 4. The third question is the main contribution of this paper, and will be answered in Section 5.. Section 6 presents conclusions.

\section{The nature of APS-ERP integration}

The first question is concerned with the types of interfaces encountered when APS planning software is interfaced with ERP transaction processing. This investigation was also done by the authors and laid down in an earlier paper (Hoogenraad and Wortmann 2007). The main results of this earlier paper are first outlined here.

When combining APS and ERP modules, the resulting architecture takes a form as depicted in Figure 1. This figure illustrates a number of points. At the right hand side, software modules of ERP transaction processing are depicted. The figure suggests that many users work in parallel, interacting with a single database. In the middle part, several ERP batch planning software modules are shown, which may or may not be implemented in a particular organisation. These modules run on the same ERP transaction database. At the left hand side, one or more APS modules are in use.

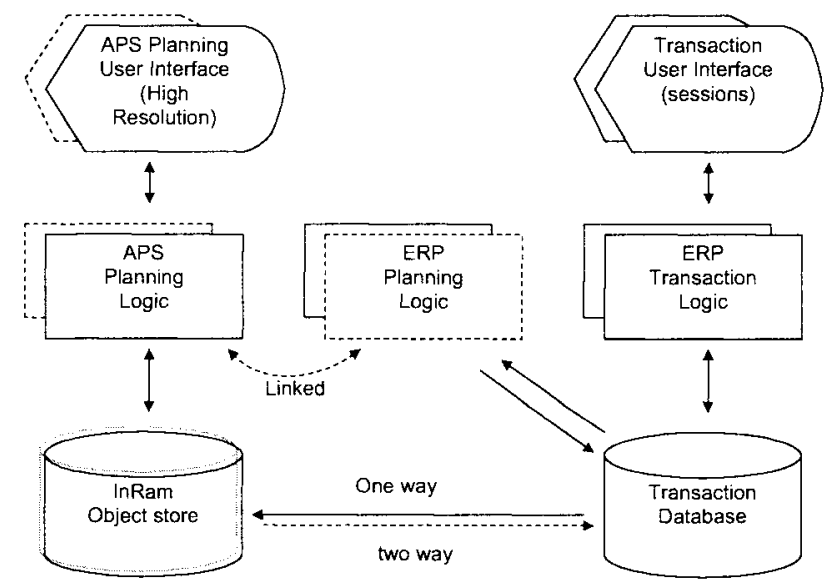

Figure 1. Collaborating software modules of ERP transaction processing, planning and APS 
Each APS module has its own (InRam) object store. The relation between an APS planning module and the ERP transaction database may be one-way or two-way. A one-way relation means that the object store is created by taking a periodic snapshot of the ERP database and by transforming this snapshot into the requires set of data objects needed for APS. A two-way relation means that the results of planning decisions made are automatically transformed inversely into meaningful ERP data and placed in the ERP database ${ }^{1}$. The arrow between APS Planning Logic and ERP planning logic with the label 'linked' represents the fact that APS planning software may either replace ERP planning software or enhance it, for each relevant planning function. In other words, most planning functions can be supported by ERP planning software, or by APS planning software or by both (or even by none of these).

When classifying interfaces between APS and ERP, there are two functional issues and two technical issues involved. As for the functional issues, the first question that should be answered is concerned with the one-way versus two-way integration (cf. Figure 1, arrows at the bottom). When the integration is one way, the APS planning software is able to perform calculations based on uploaded data, but the software cannot download any results back to ERP. Therefore, planning results have to be entered manually by the planner into ERP. In a two-way integration, the planning modules will provide ERP automatically with planning decisions. Obviously, this type requires more alignment between ERP and APS software. In particular a data model transformation during upload has to be followed by an inverse data model transformation during download. This is a complex requirement.

The second functional question pertains to the link between APS planning software and ERP planning software for a particular planning function (cf. Figure 1, arrow labelled "link"). If APS planning software replaces ERP planning software partially for a particular planning function, then the software requirements on APS can be somewhat relieved - after all, ERP planning functions will take care of many details and data modelling peculiarities

The first technical question is concerned with the complexity of the data model mapping during upload and download. As demonstrated in Hoogenraad and Wortmann 2007, these mappings can become quite complex, because there may be considerable difference in data models between ERP transaction processing and APS planning software. The second issue pertains to the timeliness constraints of upload and download. If these constraints are very tight, all kinds of provisions are needed in the interface software to guarantee data integrity

\footnotetext{
'An example of such data may be an agreed Master Production Schedule, a set of firmplanned orders, or a sequence of operations of different orders on a bottleneck machine.
} 
Table 1 below summarized these four issues.

\begin{tabular}{|r|c|c|}
\hline & Type & $\begin{array}{c}\text { Question (for each planning role where APS planning } \\
\text { software is applied): }\end{array}$ \\
\hline 1 & functional & Is it a one-way or two-way interface? \\
\hline 2 & functional & Does APS replace or enhance ERP planning software? \\
\hline 3 & technical & $\begin{array}{c}\text { How different are the data models? How complex is the } \\
\text { mapping therefore? }\end{array}$ \\
\hline 4 & technical & $\begin{array}{c}\text { What timeliness constraints have to be taken into } \\
\text { account? }\end{array}$ \\
\hline
\end{tabular}

If the integration is one-way, if APS replaces ERP planning software, if the data models are identical, and if there are no timeliness constraints, then the integration between ERP and APS is relatively straight forward. In all other cases, integrations become complex, due to the different technologies in use, and due to the amount of specific software engineering work needed.

\section{$4 \quad$ Changeability of ERP for transaction processing}

The first question on ERP changeability, was investigated on substantial literature review and case studies. This research work was documented in Wortmann et al, 2007. In this paper, changeability of ERP is treated both from a vendor perspective (denoted as ERP flexibility) and from a customer perspective (denoted as ERP adaptability). In this paper, only the customer perspective will be discussed.

When considering ERP adaptability, a key question is whether the ERP package is used as designed by the vendor, or whether it has been modified beyond the vendor's responsibility. If the package is not modified, it is configured by setting parameters. Therefore, the package may be changed by assigning new values to these parameters (Soffer et al., 2003). If the customer cannot obtain the desired functionality by setting parameters (i.e. by configuration) the package has to be modified. This happens in many cases, which implies that it cannot be avoided (Holland and Light, 1999). A modified package cannot be changed by merely changing parameters: also the modifications have to be assessed and redone.

In addition to configuration and modification, an important property of ERP systems is that they are data-oriented. Change of the ERP package may therefore lead to changes in persistent data. Because organisations need to continue the use of their data from the past, these past and current data have to be migrated to new data structures. These data migration problems are typical for transaction processing systems in business. However, when migrating ERP systems, (new) parameters with their values may have to change and logic may have changed by the vendor, which adds to the complexity of migration. When an installed ERP package is upgraded to a new version, the vendor will normally provide software tools for data migration. Despite of these tools, data migration can be a considerable effort. When ERP systems have been modified heavily, this effort can even become prohibitive. The above discussion is illustrated by Figure 2, which is taken from Wortmann et al, 2007. Section 5 will identify more factors. 


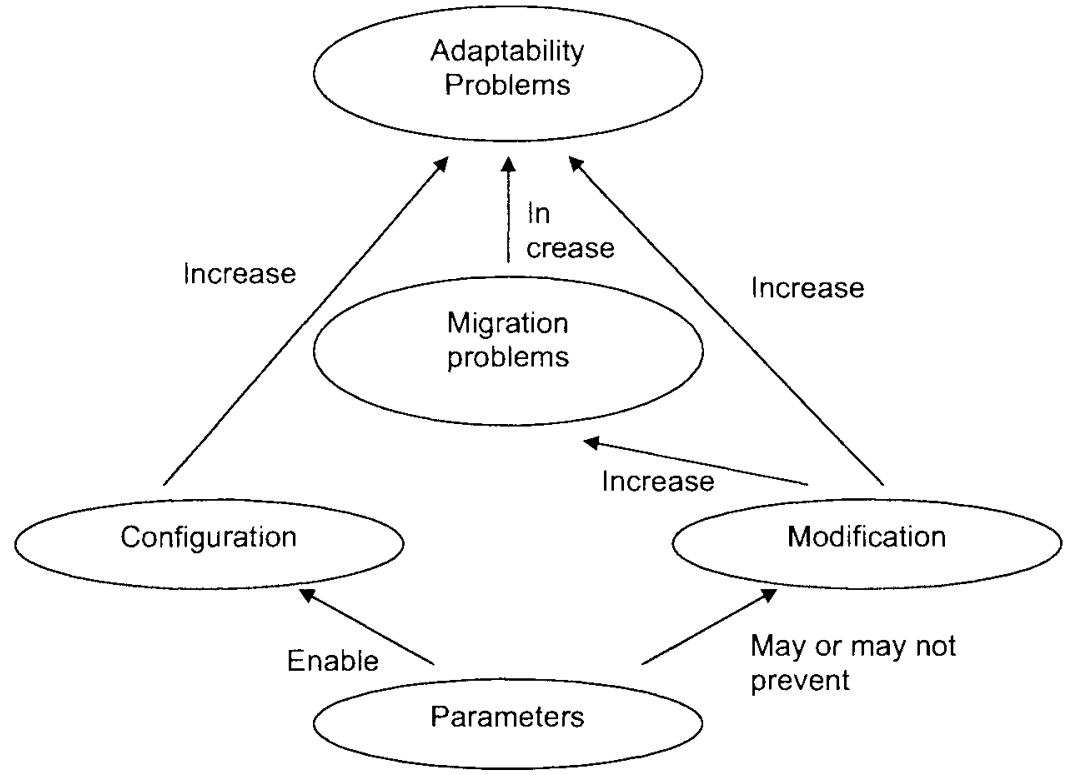

Figure 2. Factors influencing ERP adaptability

\section{Analysis of changeability of planning modules}

\subsection{Introduction}

Now the question can be addressed, whether planning modules have the same changeability issues as transaction processing systems. Looking back to Section 4 , it is clear that planning modules own very limited persistent data. Therefore, the data migration problems discussed there will probably not occur with planning software modules. Therefore, the migrations issues are depicted by a dotted ellipse in Figure 3 below.

However, parameters play an important role in planning modules of standard software packages. Actually, planning software has an abundant number of parameters, ranging from different ways to handle lead times and calendars to weighting factors when prioritising. Business changes in planning will lead to changing answers on each of the questions of Table 1 . These changing answers will lead to changing parameter values in the applicable planning modules - from APS, from ERP, or both. When using both APS and ERP planning software, the parameters have to be mutually aligned, which is in itself a mind-boggling job. Therefore, the changeability issues following from parameters shown in the lower part of Figure 2 may be expected to be present in the case of planning. These changes are driven by business developments.

Moreover, the literature studied when investigating the changeability of ERP transaction processing revealed two more factors than shown in Figure 2. These 
factors are related to multiple stakeholders and their roles and to education and training. These factors are arguably even more important for planning than for transaction processing. Planning is an organizational function where many stakeholders play a role. Therefore, subsection 5.2. analyses the effect of multiple stakeholders on changing a production management system as depicted in Figure 1. Finally, planning is a function requiring multiple skills. The role education and training is discussed in subsection 5.3. The resulting conceptual framework for change of PMS is depicted in Figure 3.

\subsection{The role of stakeholders when changing production management systems}

When implementing production management systems, the interpretations and meaning that different stakeholders attach to systems play an important role. Boonstra (2006) analyses ERP systems as redistributors of power, by interpreting implementations from a stakeholder perspective. He provides an overview of studies focusing on the meaning that people attach toward a particular technology. Boonstra concludes that: "different stakeholders can interpret ERP systems in different ways, given their own histories, interest, self-images, prospects and views. Some groups perceive the system as a means to realize certain new company objectives, while others see the system as a way to regain lost power or as a threat to legitimate local interest" ( pp. 23-24). Moreover, politics and power relationships among stakeholders are found to be a key factor when implementing an ERP system. Stakeholders have an impact on the politics, which increases ERP upgrading problems because the various stakeholders may have conflicting interests. This also applies for the planning domain, especially when different stakeholders have more interest in the supply chain planning domain or in the local planning domain.

\subsection{Education and training}

Education and training of managers and users is one of the mostly recognized critical success factor, according to Macris (2004). Therefore, Macris proposes a virtual lab implementation for these two target groups. As mentioned by Macris, the full benefits of a system can be experienced only if managers and users are using it properly. Macris remarks that costs of education and training are often underestimated: If $10-15 \%$ of the ERP implementation budget is reserved for training, this will give an organization a high chance of implementation success. Following Macris, two levels of training are required: ERP parameterization training (for the implementation professionals, providing knowledge on parameterized options), and end-user training. Since the planning modules are complex, especially when optimization engines of APS are used, it is crucial to have the involved employees trained for an implementation success. Therefore, it seems that these conclusions can safely be generalized to planning software modules, and therefore to PMS.

\subsection{Education and training}

Education and training of managers and users is one of the mostly recognized critical success factor, according to Macris (2004). Therefore, Macris proposes a virtual lab implementation for these two target groups. As mentioned by Macris, the full benefits of a system can be experienced only if managers and users are using it properly. Macris remarks that costs of education and training are often 
underestimated: If $10-15 \%$ of the ERP implementation budget is reserved for training, this will give an organization a high chance of implementation success. Following Macris, two levels of training are required: ERP parameterization training (for the implementation professionals, providing knowledge on parameterized options), and end-user training. Since the planning modules are complex, especially when optimization engines of APS are used, it is crucial to have the involved employees trained for an implementation success. Therefore, it seems that these conclusions can safely be generalized to planning software modules, and therefore to PMS.

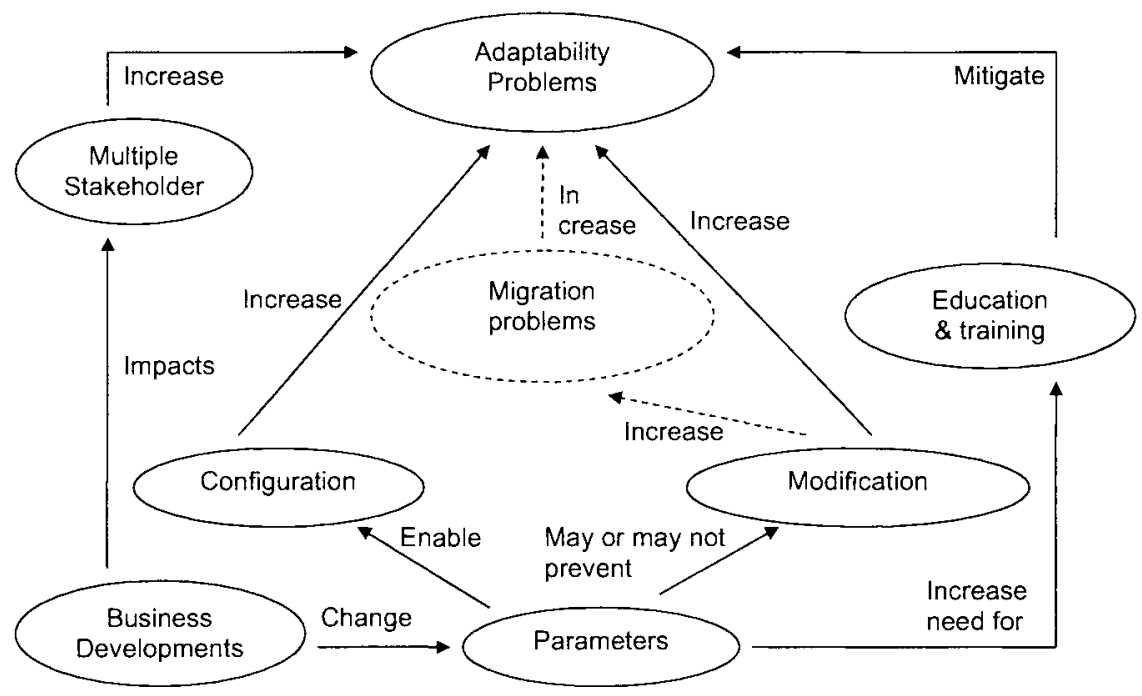

Figure 3. Factors influencing changeability of PMS systems

\section{Conclusion}

PMS systems are important for many stakeholders in an organization and its environment. Therefore, changing such systems is often a highly political process, which has to be managed properly. Moreover, is difficult to understand planning software, because both APS and ERP planning software is based on numerous parameters. Therefore, education and training of planners and other stakeholders cannot be neglected. Because of the different technologies used, changing an APS integration with ERP transaction processing is never really easy. However, the change becomes more difficult when:

- the integration between APS and ERP transaction processing is two-way

- both APS and ERP planning software are supporting the same planning function

- the data models differ substantially, such that a complex mapping is realized

- strict constraints on timeliness have to be adhered to. 
All factors above, should be taken into account when considering the changeability of production management systems.

\section{References}

1. Boonstra, A.: "Interpreting an ERP-implementation from a stakeholder perspective", International Journal of Project Management 24(1), 2006, pp. $38-52$.

2. Botta-Genoulaza, V., P.-A. Milleta, and Grabot, B.: "A survey on the recent research literature on ERP systems", Computers in Industry, Volume 56, Issue 6, August 2005, Pages 510-522

3. Grabot, B., and Botta-Genoulaza, V., "Editorial - special issue on Enteprise Resources Planning", Computers in Industry, 56 (2005), pp. 507509

4. Holland, C. and Light, B.: "A critical success factors model to ERP implementation". IEEE Software, 1999, p. 60-66.

5. Hoogenraad, M.S., and Wortmann, J.C.: "APS applications integrated with ERP: problems and solutions". Submitted to International Journal of Production Planning and Control,2007.

6. Klaus, H. Rosemann, M. and Gable, G.G.: "What is ERP?". Information Systems Frontiers, 2(2), 2000, pp. 141-162.

7. Liu, W., Chua T.J., Lam, J. Wang, F.Y., Cai, T.X., Yin, X.F., “APS,ERP and MES systems integration for Semiconductor Backend Assembly". In Seventh International Conference on Control, Automation, Robotics and Vision (ICARCV'02), Dec 2002, Singapore.

8. Macris, A.: "Enterprise Resource Planning (ERP): A virtual lab implmentation for managers and users training". SPOUDAI, OctoberDecember (2004), pp. 13-38.

9. Stadtler, H. and Kilger, C. (eds.), Supply chain Management and Advanced Planning, 2nd ed., 2002 (Springer, Berlin).

10. Soffer, P., Golany, B.,and Dori, D.: "ERP Modelling: a comprehensive approach", Information Systems 28 (2003), pp.673-690.

11. Tarn, J. M., Yen, D. C. \& Beaumont, M., "Exploring the rationales for ERP and SCM integration". In Industrial Management and Data Systems, 102 (1/2), 26-34, 2002.

12. Wiers, V.C.S., A case study on integration of APS and ERP in a steel processing plant. International Journal of Production Planning and Control 13 (no 6), 552-560, 2002 (Taylor \& Francis, London).

13. Wortmann, J. C. :"Evolution of ERP systems". In U. S. Bititchi \& A. S. Carrie (Eds.), Strategic management of the manufacturing value chain, APMS 1998, (Kluwer Academic Publishers, Amsterdam).

14. Wortmann, J.C., Hoogenraad, M.S. and Maruster, L.: "Changeability of ERP systems: a paradox". Paper submitted to Journal of Information Technology, 2007. 